\title{
Management Options for Suprasellar Cystic Craniopharyngioma: Endoscopic Transventricular Approach and Microsurgical Approach
}

\author{
Subhas K. Konar ${ }^{1} \quad$ Akshay V. Kulkarni' \\ Sameer Peer ${ }^{2}$ Vivek Lanka \\ ${ }^{1}$ Department of Neurosurgery, National Institute of Mental Health \\ and Neurosciences, Bengaluru, Karnataka, India \\ ${ }^{2}$ Department of Neuroimaging and Interventional Radiology, \\ National Institute of Mental Health and Neurosciences, Bengaluru, \\ Karnataka, India \\ J Neurosci Rural Pract 2021;12:343-349.
}

\author{
Address for correspondence Dhaval Shukla, MCh, Department of \\ Neurosurgery, National Institute of Mental Health and Neurosciences, \\ Bengaluru 560029 Karnataka, India (e-mail: neurodhaval@rediffmail.com).
}

\begin{abstract}
Objective The treatment of cystic craniopharyngioma in children is varied. The treatment ranges from radical excision to direct radiotherapy. As the morbidity of excision is high, more conservative approaches are used. Transventricular endoscopy is a minimally invasive treatment for cystic craniopharyngiomas. The objective of this study is to compare the outcome of microscopic versus endoscopic transventricular approach for cystic craniopharyngioma.

Methods This is a retrospective study of series of children managed with microscopic excision and endoscopic transventricular approach for suprasellar cystic craniopharyngiomas. Operative details, visual outcome, endocrinological outcome, tumor-related cyst recurrence rate, and complication were compared between microscopic and endoscopic groups.

Results A total of 28 children underwent microscopic excision and 14 children underwent endoscopic procedure. The anesthesia time was significantly lower with endoscopic as compared to microscopic group $(p=0.0001)$ as well as blood loss during surgery $(p=0.0001)$. Hospital stay after surgery was shorter in endoscopic group. Incidence of diabetes insipidus was more in microscopic group (25\%) compared to endoscopic group (7.14\%). Visual outcome was almost same with approaches.

Keywords

- craniopharyngioma

- suprasellar

- microscopy

- endoscopy Requirement of hormone replacement was more in microscopic group than in endoscopic group $(p=0.006)$. Incidence of cyst recurrence was more in microscopic $(39.3 \%)$ compared to endoscopic group (7.7\%).

Conclusion Endoscopic transventricular approach is a safe alternative for initial treatment of suprasellar cystic craniopharyngioma in children.
\end{abstract}

\section{Introduction}

Though complete resection of craniopharyngioma is desirable for lower recurrence rates, it is hindered by functional preservation. Currently, a trend toward less radical surgical approaches is observed. In a multicenter study of children and

published online April 1, 2021
DOI https://doi.org/

10.1055/s-0041-1722839 ISSN 0976-3147. adolescents with craniopharyngioma, KRANIOPHARYNGEOM 2007, it was observed that the realized treatment was more radical $(p=0.01)$ in patients recruited between 2001 and 2007 (38\%) when compared with patients treated between 2007 and $2012(18 \%) .{ }^{1}$ Despite less radical resection in the later cohort,

(c) 2021. Association for Helping Neurosurgical Sick People. This is an open access article published by Thieme under the terms of the Creative Commons Attribution-NonDerivative-NonCommercial-License, permitting copying and reproduction so long as the original work is given appropriate credit. Contents may not be used for commercial purposes, or adapted, remixed, transformed or built upon. (https://creativecommons.org/licenses/by-nc-nd/4.0/). Thieme Medical and Scientific Publishers Pvt. Ltd. A-12, 2nd Floor, Sector 2, Noida-201301 UP, India 
$65 \%$ of patients had hypothalamic lesions. Cystic craniopharyngiomas present a unique challenge because of the possibility of recurrence of cyst irrespective of the modality of initial treatment. ${ }^{2}$ Almost $90 \%$ of craniopharyngiomas have a cystic component. ${ }^{3}$ The presence of a cyst in craniopharyngioma can account for major total bulk of the tumor, and a predominantly cystic tumor is seen in $60 \%$ of craniopharyngiomas. ${ }^{4}$ The traditional approach to cystic craniopharyngioma is a variable extent of microsurgical resection. Ommaya reservoir is often placed in the residual cyst for repeated aspiration or intracavitary therapy. ${ }^{5}$ However, the malposition of reservoir is not uncommon. ${ }^{6,7}$ In such circumstances, a neuroendoscopic approach provides a less invasive and more accurate technique to deal with cystic craniopharyngiomas. ${ }^{6,8}$ Since 2013, we follow the endoscopic transventricular approach for intra- and paraventricular cystic craniopharyngiomas. We compared the outcome of the microscopic approach and the endoscopic transventricular approach for the treatment of suprasellar cystic craniopharyngioma operated in a single neurosurgical unit.

\section{Methods}

The present study is retrospective review of case files of children with cystic craniopharyngioma operated in our hospital in a single neurosurgical unit from 2009 to 2018. Institute ethics committee clearance was not required as it was only retrospective review of data. The clinical features, imaging findings, surgical approach, complication, and outcome were noted. Children aged 18 years or less with purely or predominantly cystic craniopharyngioma arising within or extending inside third ventricle causing obstructive hydrocephalus were included. All children underwent neurological and neuro-ophthalmological examination before surgery and at follow-up. All children underwent laboratory investigations for morning serum cortisol and thyroid function tests. All children underwent preoperative magnetic resonance imaging (MRI) of brain and computerized tomography (CT) scans after surgery and at follow-up. All the images were re-reviewed, and the tumors were classified and the volumes measured independently by two neuroradiologists (V.L. and S.P.). Before 2013, all children underwent craniotomy, variable extent of the resection of solid and cystic portion of tumor and placement of catheter in the residual cyst. The catheter was connected to subgaleal reservoir for aspiration of cyst in case of recurrence. From the year 2013, the preferred treatment of cystic craniopharyngioma was precoronal frontal burr hole, neuroendoscopic transcortical transventricular aspiration of cyst, and placement of catheter in the cyst connected to subgaleal reservoir (-Figs. 1 and 2). Predominantly, cystic tumors underwent microscopic excision with or without reservoir were included in the present study for comparison of outcome. Those who underwent resection of solid tumor were not included for analysis. Recurrence was defined as symptomatic refilling of cyst or increase in size of residual solid tumor. The cystic recurrences were treated with repeated aspiration of the cyst. Radiotherapy was deferred in younger children as much as possible so that the children can achieve full growth potential before radiotherapy. Postoperative radiotherapy was advised for children more than 7 years of age. Intracavitary therapy was not given to any children.
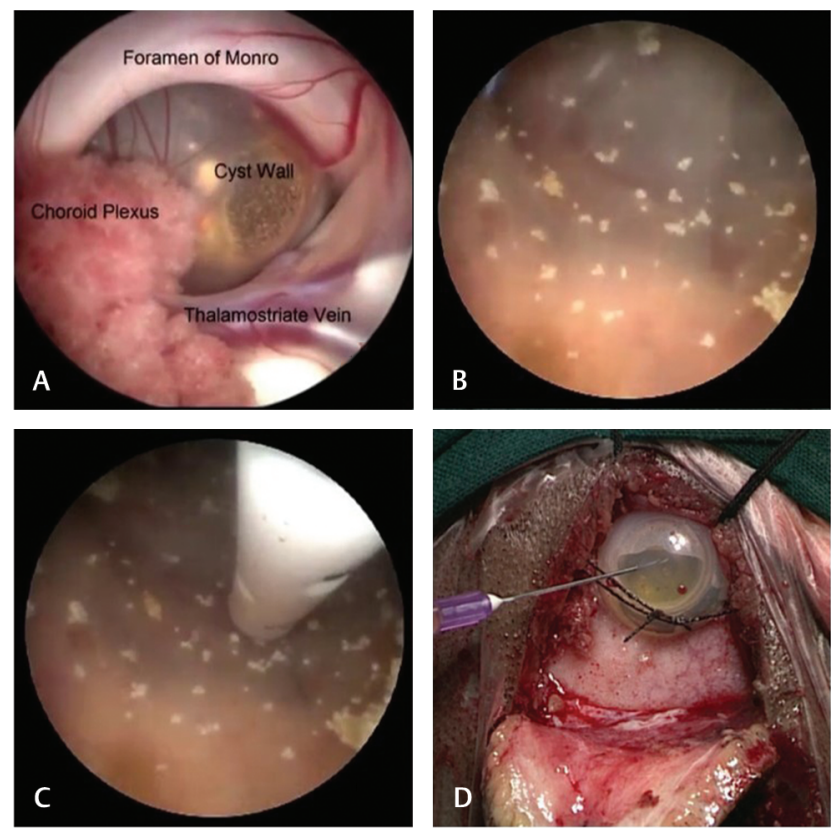

Fig. 1 Endoscopic views of operative steps. (A) Cyst seen at foramen of Monro. (B) Inner view of cystic craniopharyngioma showing calcifications after thorough irrigation. (C) Catheter inside the cyst. (D) Subgaleal reservoir.
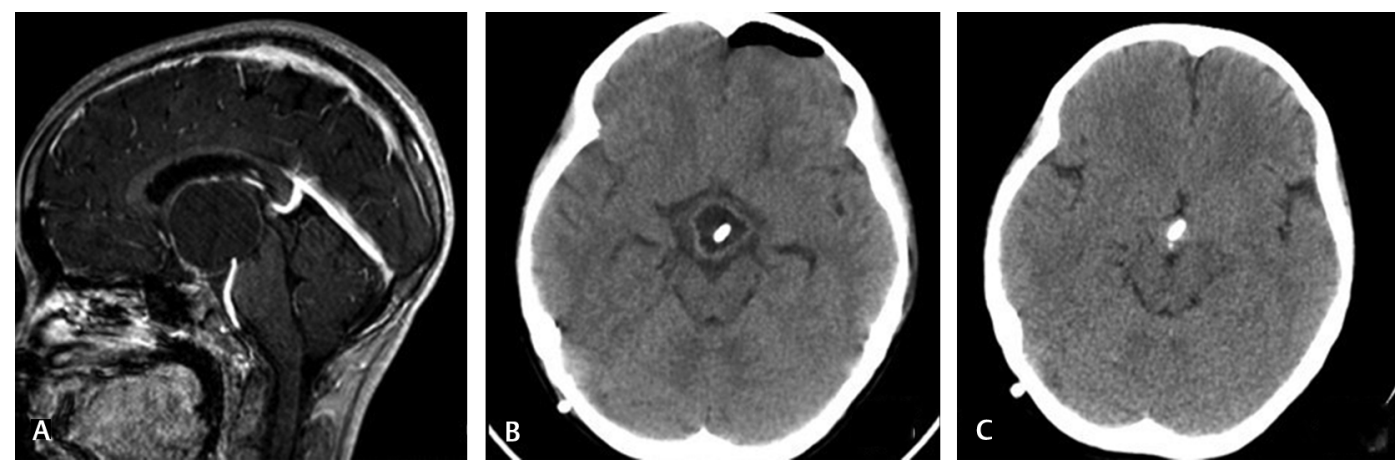

Fig. 2 Imaging of a 12-year-old girl who presented with clinical features of raised intracranial pressure. (A) Preoperative magnetic resonance imaging showing cystic craniopharyngioma in third ventricle. (B) Postoperative CT scan showing collapse of cyst. (C) Computed tomography scan after radiotherapy, 27 months after surgery, showing complete collapse of cyst. 


\section{Statistical Analysis}

Data were entered in Excel sheet (Microsoft Corporation, United States), and analysis was done by using SPSS software version 20 (IBM Inc, United States). Chi-square test and Fisher's exact tests (two-tailed) were used for categorical values and Mann-Whitney $U$ test for continuous variables. $Z$ score analysis was utilized for proportion. Statistical significance was defined as $p$-value $<0.05$.

\section{Results}

A total of 28 children underwent craniotomy and microscopic excision, and 14 children underwent the neuroendoscopic procedure. The intracystic catheter connected to subgaleal reservoir was placed in all cases of endoscopic group and in 14/28 cases in microscopic group. The clinical features in both the groups were comparable ( - Table $\mathbf{1}$ ). The imaging comparisons are detailed in $\mathbf{- T a b l e ~} \mathbf{2}$. Though more children in microscopic group had vision impairment, the difference was not significant. However, there were important differences in operative details and postoperative outcomes between two groups (-Table 3). A ventriculoperitoneal (VP) shunt was already done preoperatively in $21.4 \%$ in the endoscopic group and $35.7 \%$ in microscopic group. The endoscopy was done through the side of dilated ventricle. The anesthesia time was significantly lower with endoscopic as compared to microscopic technique ( $122.5 \pm 33.7$ vs. $224.6 \pm 42.9$ minutes; $p=0.0001$ ). The blood loss was also significantly lower in the endoscopic group (29.2 \pm 12.1 vs. $164.6 \pm 97.3 \mathrm{~mL} ; p=0.0001$; - Fig. 3 ). The patients who underwent an endoscopic approach had a reduced hospital stay as compared to the patients in the microscopic group ( 4 vs. 7 days; $p=0.001$ ). The incidence of diabetes insipidus was more in the microscopic group (25\%) as compared to the endoscopic group (7.1\%), but the difference was not

Table 1 Demographic and clinical features

\begin{tabular}{|l|l|l|}
\hline & $\begin{array}{l}\text { Endoscopic } \\
(\boldsymbol{n}=14)\end{array}$ & $\begin{array}{l}\text { Microscopic } \\
(\boldsymbol{n}=28)\end{array}$ \\
\hline Demographics & & \\
\hline Age in years (median, IQR) & $11(5-13)$ & $10(7-13)$ \\
\hline Sex (M:F) & $1: 2.5$ & $1: 1$ \\
\hline Clinical features & $11(78.5 \%)$ & $24(85.7 \%)$ \\
\hline Headache & $10(71.4 \%)$ & $14(50 \%)$ \\
\hline Vomiting & 0 & $4(14.2 \%)$ \\
\hline Seizures & $2(14.2 \%)$ & $2(7.14 \%)$ \\
\hline Miscellaneous & $2(14.2 \%)$ & $1(3.6 \%)$ \\
\hline Motor weakness & $7(50 \%)$ & $23(82.1 \%)$ \\
\hline Vision impairment & 0 & $3(10.7 \%)$ \\
\hline Cranial nerve symptoms & $1(7.1 \%)$ & $2(7.1 \%)$ \\
\hline $\begin{array}{l}\text { Anterior pituitary hormone } \\
\text { deficiency }\end{array}$ & 0 & 0 \\
\hline $\begin{array}{l}\text { Preoperative diabetes } \\
\text { insipidus }\end{array}$ & & \\
\hline
\end{tabular}

Abbreviations: F, female; IQR, interquartile range; M, male. statistically significant. The incidences of other complications were not significantly different between two groups. The only mortality in entire cohort was in the endoscopic group due to a systemic cause. There was no procedure-related mortality.

The follow-up was not available for $1 / 14$ children in endoscopic group and 2/28 children in microscopic group. The follow-up duration for both the groups was comparable (-Table 4). All patients underwent periodic CT scans. All patients underwent a CT scan on the first postoperative day. In the endoscopy group, the CT scans were repeated at median of 7, 11, 17, and 34 months after surgery (-Fig. 4). In the microscopy group, the CT scans were repeated at a median of 5, 9, 23, and 49 months after surgery (-Fig. 5). There was reduction in the volume of tumor over time in both groups (-Fig. 6). The clinical condition at follow-up as measured by the Lansky performance scale was similar in both groups. There was no significant difference in the postoperative vision outcome, stunted growth, and need for VP shunt. The incidence of hormone deficits and need for replacements was significantly lower in the endoscopic group (15.3 vs. $57.1 \% ; p=0.006)$. The cystic recurrence was more common in the microscopic group (39.3 vs. $7.69 \% ; p=0.02$ ). One patient in endoscopy group required reaspiration once at 12 months after surgery. Three patients in microscopic group required reaspiration; one patient at 31 months and another patient at 41 months. One patient required reaspiration thrice at 16 , 24 , and 44 months after surgery.

\section{Discussion}

Management of cystic craniopharyngioma is controversial in literature. ${ }^{9-11}$ Some surgeons have suggested radical resection of the cystic part along with excision of the solid part. On the contrary, few surgeons have followed a conservative approach like the fenestration of the cyst, biopsy and/or placement of catheter reservoir. ${ }^{12,13}$ The endoscopic transventricular route is an alternative approach for the treatment of cystic craniopharyngioma. ${ }^{14-16}$ Postoperative radiation therapy has been advised in some cases in older children. ${ }^{11}$ Surgical approaches are also varied among the surgeons. Recently, endoscopic transnasal approach has become popular for the

Table 2 Imaging characteristics

\begin{tabular}{|c|l|l|}
\hline & $\begin{array}{l}\text { Endoscopic } \\
(\boldsymbol{n}=14)\end{array}$ & $\begin{array}{l}\text { Microscopic } \\
(\boldsymbol{n}=\mathbf{2 8})\end{array}$ \\
\hline Topographical classification & & \\
\hline Sellar-suprasellar & 0 & $4(14.3 \%)$ \\
\hline Infundibulo-tuberal & $6(42.8 \%)$ & $3(10.7 \%)$ \\
\hline Pseudo third ventricular & $4(28.6 \%)$ & $6(21.4 \%)$ \\
\hline $\begin{array}{l}\text { Suprasellar secondary } \\
\text { third ventricular }\end{array}$ & $3(21.4 \%)$ & $6(21.4 \%)$ \\
\hline Third ventricular & $1(7.1 \%)$ & $3(10.7 \%)$ \\
\hline Not available & 0 & $6(21.4 \%)$ \\
\hline Preoperative VP shunt & $3(21.4 \%)$ & $10(35.7 \%)$ \\
\hline
\end{tabular}

Abbreviation: VP, ventriculoperitoneal. 
Table 3 Operative details and complications

\begin{tabular}{|l|l|l|l|}
\hline & Endoscopic $(\boldsymbol{n}=14)$ & Microscopic $(\boldsymbol{n}=28)$ & $\boldsymbol{p}$-Value ${ }^{\text {a }}$ \\
\hline Operative findings & & & \\
\hline Anaesthesia time (min), mean (SD) & $122.5(33.7)$ & $224.6(42.9)$ & 0.0001 \\
\hline Blood loss (mL), mean (SD) & $29.2(12.1)$ & $164.6(97.3)$ & 0.0001 \\
\hline Hospital stay in days, median (IQR) & $4(2)$ & $7(4)$ & 0.001 \\
\hline Preoperative shunt & $4(28.5 \%)$ & $11(39.2 \%)$ & 0.48 \\
\hline Complication & & & \\
\hline Wound dehiscence & 1 & 1 & \\
\hline CSF leak & 0 & 0 & \\
\hline Subdural effusion & 1 & 1 & \\
\hline Seizure & 0 & 4 & \\
\hline Motor weakness & 0 & $7(25 \%)$ & 0.16 \\
\hline Diabetes insipidus (\%) & $1(7.1 \%)$ & 0 & \\
\hline Mortality & 1 & & \\
\hline
\end{tabular}

Abbreviations: CSF, cerebrospinal fluid; SD, standard deviation; IQR, interquartile range.

${ }^{a} p$-Value could not be computed for variables with low numbers.
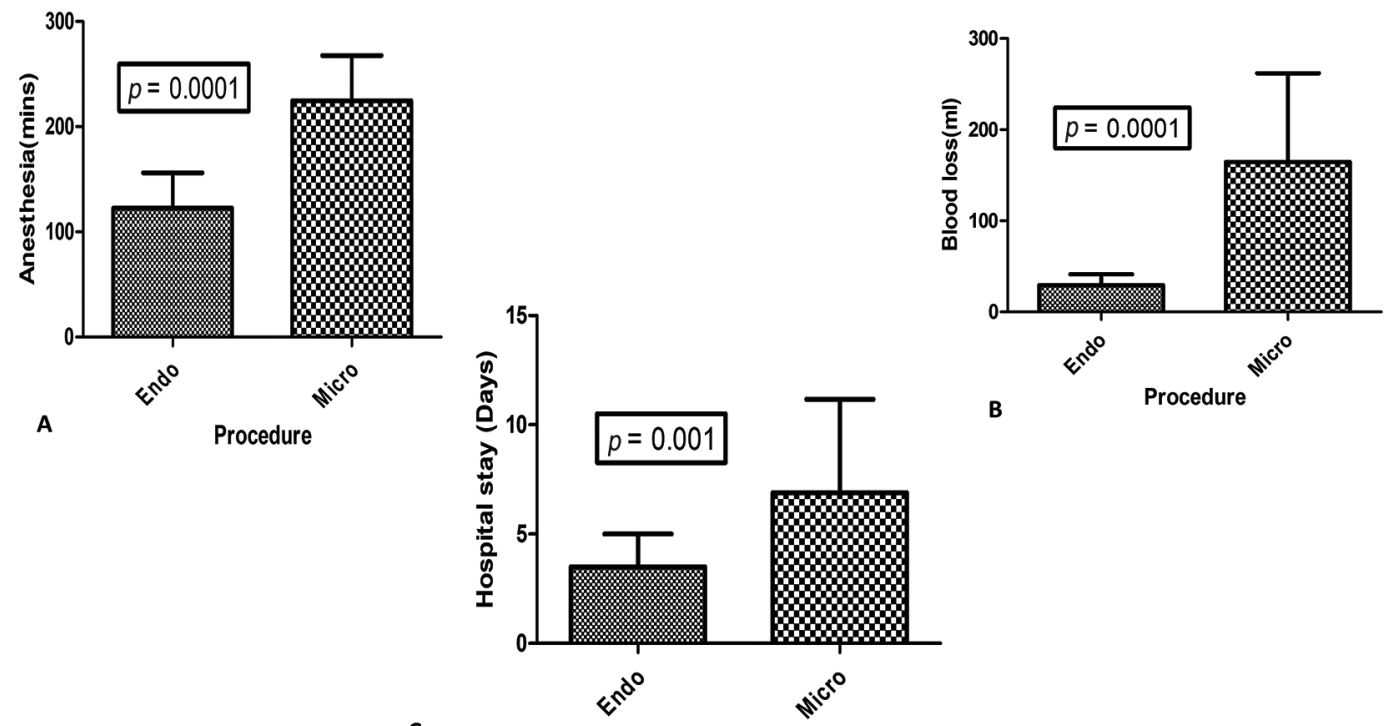

C

Procedure

Fig. 3 Bar diagrams representation of comparison of anesthesia time (A), blood loss (B), and hospital stay (C) between endoscopic transventricular approach versus craniotomy microscopic approach.

resection of craniopharyngiomas. Elliott et $\mathrm{al}^{9}$ published a systemic review of comparison between microscopic versus transnasal endoscopic approach, but direct comparison between microscopic and endoscopic transventricular is not published in the literature. Most craniopharyngiomas with supradiaphragmatic, paraventricular, or intraventricular extensions (type C, D, E, and F according to Yasargil's classification) are candidates for endoscopic transventricular approach. ${ }^{17}$

Endoscopic transventricular approach has been described earlier as case reports or small case series. ${ }^{1,2,4,6,13,16}$ In these reports whenever attempt at resections was made, the morbidity was high. The safest endoscopic transventricular approach is the fenestration of cyst and placement of intracystic catheter connected to subgaleal reservoir. This approach has been used traditionally through craniotomy microscopically. We compared the outcome with the microscopic approach. In the present study, we found that the endoscopic approach was less time consuming, resulted in less blood loss, and required less number of days in hospital. The incidence of diabetes insipidus was also less with endoscopic transventricular approach. The outcome of endoscopic approach was superior as compared to craniotomy microscopic approach in terms of requirement of hormonal 
Table 4 Outcome

\begin{tabular}{|c|c|c|c|}
\hline & Endoscopic $(n=13)$ & Microscopic $(n=26)$ & $p$-Value ${ }^{\text {a }}$ \\
\hline Follow-up duration in months, median (range) & $9(1-46)$ & $11(1-120)$ & \\
\hline $\begin{array}{l}\text { Clinical condition at follow-up, Lansky performance scale (mean } \\
\text { score) }\end{array}$ & 94 & 90 & \\
\hline \multicolumn{4}{|l|}{ Vision } \\
\hline Same & $12(85.7 \%)$ & $20(71.4 \%)$ & \\
\hline Improved & $2(14.3 \%)$ & $4(14.3 \%)$ & \\
\hline Worsen & 0 & $2(7.1 \%)$ & \\
\hline Stunted growth & $2(15.3 \%)$ & $2(7.7 \%)$ & 0.45 \\
\hline Hormone replacement & $2(15.3 \%)$ & $16(57.1 \%)$ & 0.006 \\
\hline Radiotherapy received & $5(38.4 \%)$ & $11(39.3 \%)$ & 0.81 \\
\hline Postoperative shunt & $1(7.7 \%)$ & $4(15.3 \%)$ & 0.49 \\
\hline Cystic recurrence & $1(7.7 \%)$ & $11(39.3 \%)$ & 0.02 \\
\hline Reaspiration & 1 & 3 & \\
\hline Time of cystic recurrence duration in months & 5 & 10 & \\
\hline Solid portion recurrence & 0 & $2(7.7 \%)$ & \\
\hline
\end{tabular}

${ }^{a} p$-Value could not be computed for variables with low numbers.

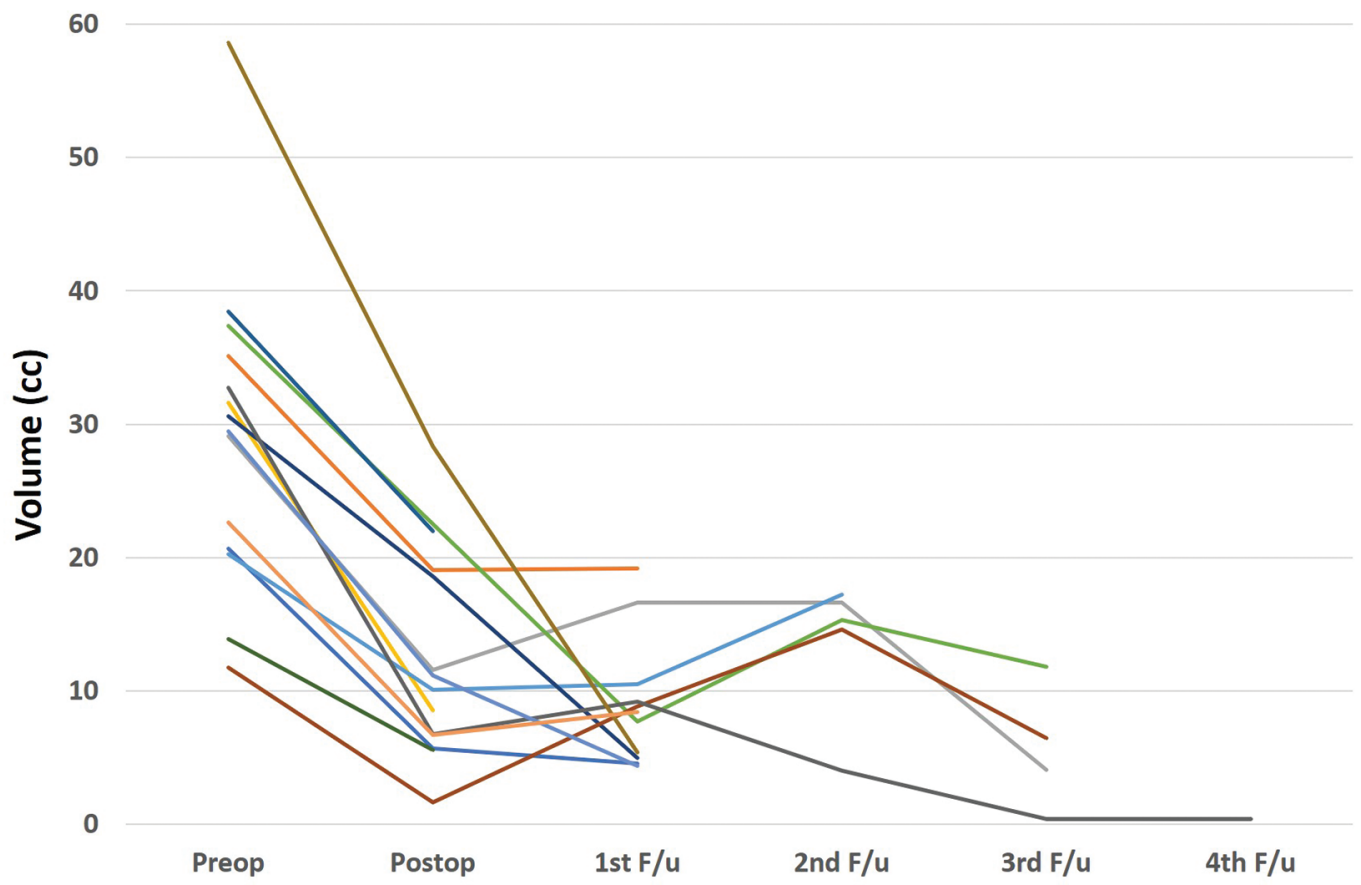

Fig. 4 Graph showing reduction in volume of tumor with time for each patient who underwent endoscopic surgery.

replacement and recurrence. The endoscopic approach does not lead to manipulation of pituitary stalk and hypothalamus. The catheter is placed directly under vision; hence, the risk of malposition is less. As the cyst communicates in ventricle the chance of cyst recurrence is also less.

\section{Limitation}

Major limitation of transventricular endoscopic approach is that a radical excision cannot be achieved. It should not be attempted in any case because of the fear of causing hypothalamic damage as in microsurgical procedure. The feasibility and success of radical resection mainly depends on the availability of surgical expertise and postoperative endocrinologic support. It is also dependent on the size and extent of the tumor, whether the tumor is primary or recurrent, the clinical condition of the patient, and the societal resources available to cope with potential postoperative deficits. The second major issue is that the median duration of follow-up 


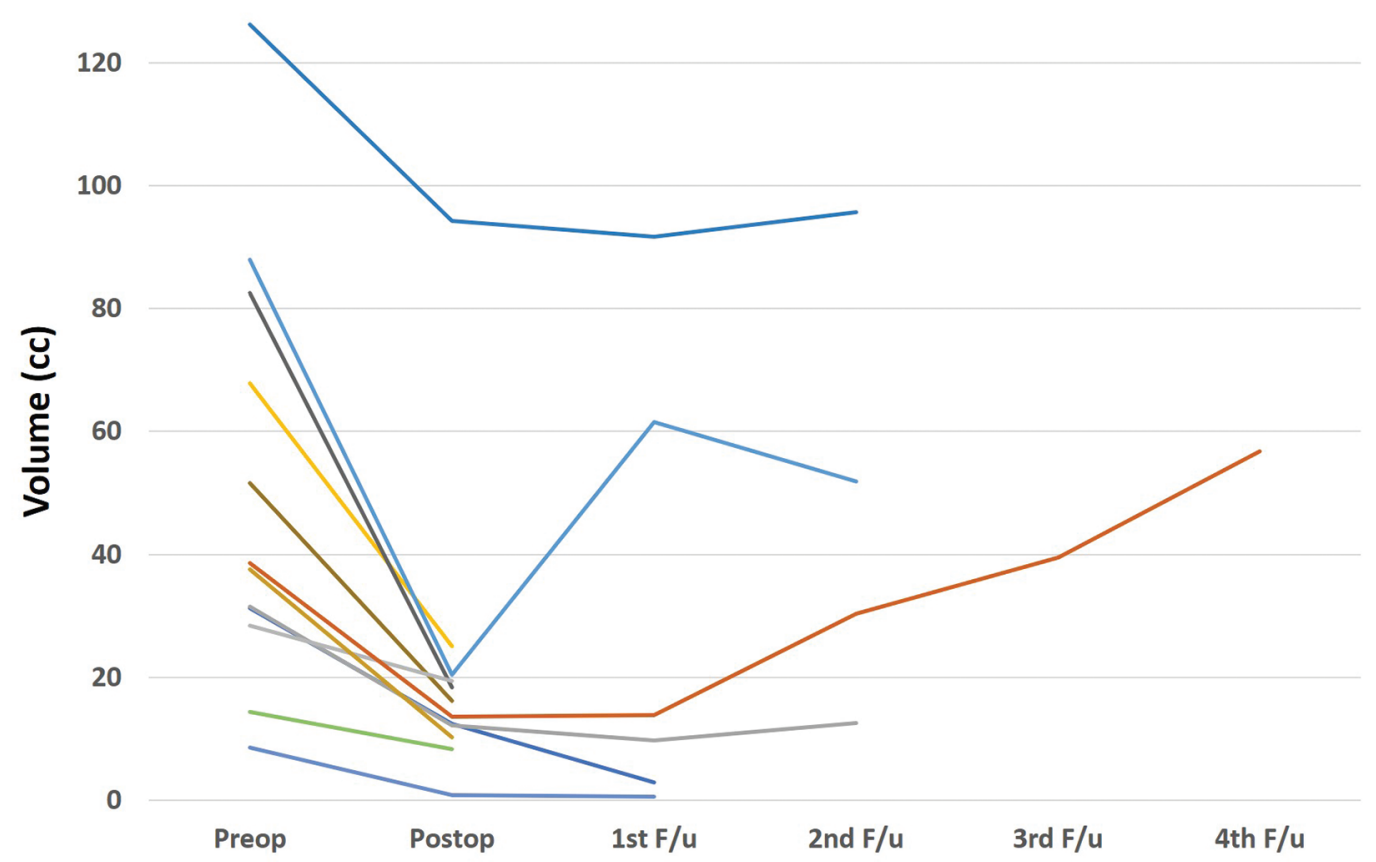

Fig. 5 Graph showing reduction in volume of tumor with time for each patient who underwent microscopic surgery.

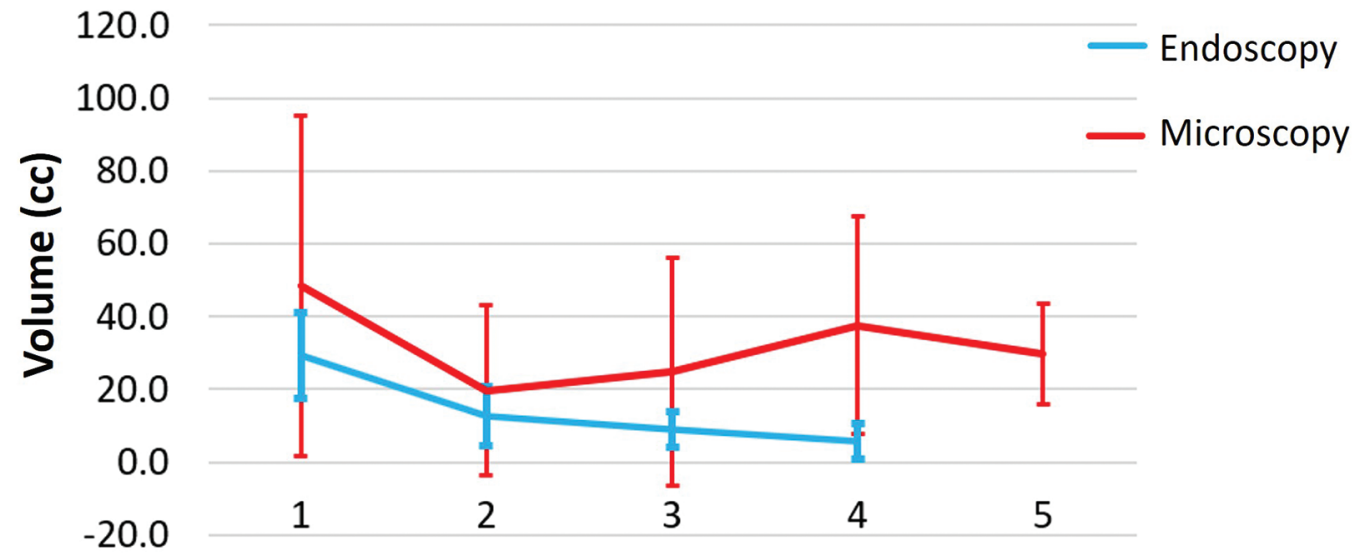

Fig. 6 Graph showing comparison of volume of tumor with time for endoscopic and microscopic surgery.

is 9 months in the endoscopic group and 11 months in the microscopic group. This duration is too short to comment on recurrence of a tumor that is known to recur even several years after radiation therapy. However, the present study was a feasibility study to look for an alternative technique for suprasellar cystic craniopharyngioma. In short term, both endoscopic transventricular and microsurgical techniques are comparable. We did not look for functional and cognitive sequelae such as school performance for comparison.

\section{Conclusion}

The outcome of cystic craniopharyngioma located in sellar area with minimal suprasellar component via endoscopic transnasal route is better than transcranial approach. ${ }^{9}$ The morbidity of surgery for suprasellar cystic craniopharyngioma is high either in transcranial microscopic procedure or endoscopic transnasal procedure. ${ }^{10}$ The advantages of the transventricular endoscopic approach are minimal invasiveness and lower morbidity compared to microsurgical procedures. The transventricular endoscopic approach to cystic craniopharyngiomas allows control of mass effect, preservation of function, and integration with other therapeutic means (microsurgery, radiation therapy, and radiosurgery). After endoscopic cyst aspiration once the cyst collapses and becomes free from the third ventricular floor, it is easier to excise completely later if required. Endoscopic fenestration, aspiration of cyst, and placement of catheter connected to reservoir followed by radiation is the safe treatment for cystic craniopharyngioma growing into the third ventricle. With the current trend of minimal surgery and radiotherapy to preserve quality of life, transventricular endoscopy for cystic craniopharyngioma 
provides an optional surgical tool and may be employed as the initial treatment when indicated.

\section{Funding}

None.

\section{Conflict of Interest}

None declared.

\section{References}

1 Hoffmann A, Warmth-Metz M, Gebhardt U, et al. Childhood craniopharyngioma - changes of treatment strategies in the trials KRANIOPHARYNGEOM 2000/2007. Klin Padiatr 2014;226(3):161-168

2 Muller HL. Childhood craniopharyngioma. Recent advances in diagnosis, treatment and follow-up. Horm Res 2008;69(4):193-202

3 Barajas MA, Ramírez-Guzmán G, Rodríguez-Vázquez $C$, et al. Multimodal management of craniopharyngiomas: neuroendoscopy, microsurgery, and radiosurgery. J Neurosurg 2002;97(5, Suppl):607-609

4 Delitala A, Brunori A, Chiappetta F. Purely neuroendoscopic transventricular management of cystic craniopharyngiomas. Childs Nerv Syst 2004;20(11-12):858-862

5 Gutin PH, Klemme WM, Lagger RL, MacKay AR, Pitts LH, Hosobuchi Y. Management of the unresectable cystic craniopharyngioma by aspiration through an Ommaya reservoir drainage system. J Neurosurg 1980;52(1):36-40

6 Mori R, Joki T, Nonaka Y, Ikeuchi S, Abe T. Parallel insertion endoscopic technique for precise catheter placement in cystic craniopharyngiomas. J Neurol Surg A Cent Eur Neurosurg 2014;75(6):442-446

7 Zanon N, Cavalheiro S, da Silva MC. Does the choice of surgical approach to insert an intratumoral catheter influence the results of intratumoral cystic treatment? Surg Neurol 2008;70(1):66-69, discussion 69

8 Pettorini BL, Tamburrini G, Massimi L. Caldarelli M, Di Rocco C. Endoscopic transventricular positioning of intracystic catheter for treatment of craniopharyngioma. Technical note. J Neurosurg Pediatr 2009;4(3):245-248

9 Elliott RE, Jane JA Jr, Wisoff JH. Surgical management of craniopharyngiomas in children: meta-analysis and comparison of transcranial and transsphenoidal approaches. Neurosurgery 2011;69(3):630-643, discussion 643

10 Macarthur DC, Buxton N, Vloeberghs M, Punt J. The effectiveness of neuroendoscopic interventions in children with brain tumours. Childs Nerv Syst 2001;17(10):589-594

11 Ali ZS, Bailey RL, Daniels LB, et al. Comparative effectiveness of treatment options for pediatric craniopharyngiomas. J Neurosurg Pediatr 2014;13(2):178-188

12 Hellwig D, Bauer BL, List-Hellwig E. Stereotactic endoscopic interventions in cystic brain lesions. Acta Neurochir Suppl (Wien) 1995;64(Supplement 64) :59-63

13 Nakamizo A, Inamura T, Nishio S, Inoha S, Ishibashi H, Fukui M. Neuroendoscopic treatment of cystic craniopharyngioma in the third ventricle. Minim Invasive Neurosurg 2001;44(2):85-87

14 Cinalli G, Spennato P, Cianciulli E, Fiorillo A, Di Maio S, Maggi G. The role of transventricular neuroendoscopy in the management of craniopharyngiomas: three patient reports and review of the literature. J Pediatr Endocrinol Metab 2006;19(Suppl 1) :341-354

15 Gaab MR, Schroeder HW. Neuroendoscopic approach to intraventricular lesions. J Neurosurg 1998;88(3):496-505

16 Shukla D. Transcortical transventricular endoscopic approach and ommaya reservoir placement for cystic craniopharyngioma. Pediatr Neurosurg 2015;50(5):291-294

17 Yaşargil MG, Curcic M, Kis M, Siegenthaler G, Teddy PJ, Roth P. Total removal of craniopharyngiomas. Approaches and long-term results in 144 patients. J Neurosurg 1990;73(1):3-11 